\title{
A Socio-Technical Approach to Participatory Design: Learning from Scenario-Based Planning Practices
}

\author{
MING-CHUN LEE \\ University of North Carolina at Charlotte
}

\begin{abstract}
Architects and community planners depend on proper tools to engage and interact with citizens. Scenario planning is one of such tools enabling designers and community members to work together to address uncertainty in future community growth and develop a range of possible design solutions that may lead to alternative future conditions. This essay traces the history of scenario planning and attempts to understand its application to community design from a socio-technical perspective, which sees community design as both spatial inquiry and communicative action. This essay then discusses a demonstration project conducted between 2011 and 2014 in Texas, for which scenario analysis methods were employed to conduct community-based design processes. Key steps to implement this scenario planning project, such as visioning, compiling data, conducting community design workshop, drafting future community growth plan, are highlighted in the essay to illustrate this unique socio-technical approach to participatory design.
\end{abstract}

\section{INTRODUCTION}

Samuel Mockbee once argued that the practice of architecture not only requires individual participation in the profession, but also requires active civic engagement. He stressed the importance of a deeper democratic purpose of inclusion in energizing one's community. Many methods for citizen participation have been introduced in architecture and its allied fields such as urban planning and design. Scenario planning is one of these methods enabling architects and urban designers to engage citizens in community design. It allows participants in public meetings to develop a range of possible design solutions that may lead to alternative future conditions. By examining the pros and cons of these scenarios against a set of measures, a preferred design scenario may emerge to become the selected solution.

This type of community-based practices has its root in the field of participatory design, which is a response to the demand to have voices heard and ideas taken from those who are involved in the design process. It sees community members as citizen designers who play an active role in shaping the formulation of both the design process and its ultimate results.

Scenario planning relies on mapping software to provide contextual information and enable "painting" on the map to brainstorm ideas for possible improvements in a community. This type of community-based practices is typically conducted at the regional scale, there are however many successful cases in which scenario planning was applied effectively to small community design processes at the neighborhood scale (Lee, 2017). Examples include many projects completed in Oregon, Texas, and Utah in recent years. Both two approaches are important and complementary to one another in a sequential way with a regional vision first being laid out as an underlying planning framework followed by a more locally-focused design approach tailored to the specifics and uniqueness of a smaller jurisdiction.

This paper discusses a series of community design projects conducted between 2011 and 2014 for a selection of five small cities and neighborhoods in Central Texas. These projects employed scenario analysis methods as a way to connect a regional planning framework to local community design processes. This paper details those key steps taken to implement these scenario planning exercises, including visioning, compiling data, conducting community workshops, and drafting of future community growth plans.

\section{COMMUNITY DESIGN AS SPATIAL PLANNING / TECHNICAL PERSPECTIVE}

Spatial planning shapes the geographical area in which we live. It incorporates various methods to influence the distribution of people, resources, and development activities in spaces of various scales.

Community design is inherently a spatially oriented profession. As spatial planning, it gives geographical expression to the economic, social, cultural and environmental policies of society. It is at the same time a rational and scientific discipline, an administrative technique and a policy developed as an interdisciplinary and comprehensive approach directed towards a balanced community development and the physical organization of space according to an overall strategy that is supported by sound technical knowledge and investigations.

On a daily basis, community designers are confronted with a myriad of ad hoc decisions which require accurate and current spatial data. Their tasks rely on a set of procedures that enable them to convert a diverse amount of spatial data into the type of information needed to support the decision-making process. The nature of the data distinguishes community design from other data business because virtually all design-related data is intimately related to geography or spatial location. 
Community design provides structured processes in which decision-making and problem-solving occur (Kliskey, 1995). Within these structured processes, information becomes a key ingredient to successful decision-making. Community design therefore is considered to be an information processing activity. All relevant information must be stored, managed, made available and presented in a suitable and organized form for use at different stages in the design process (Scholten et al, 1990).

\section{COMMUNITY DESIGN AS COMMUNICATIVE PLANNING / SOCIO-POLITICAL PERSPECTIVE}

In contrast to its rational and technical aspect, community design is best seen as not only the activity of spatial analysis performed by an isolated individual or organization but also as an ongoing process of social design, interactive dialogue, and debate in which designers, public officials, and the general public attempt to decide together how to best manage the collective concerns of society (Healey 1992, 1997).

Moving away from its analytical nature requiring spatial data and information processing, community design has increasingly become a process of structured negotiation and deliberation that requires greater participation from those who are involved in its processes. It needs so-called soft data that can reveal the social values embedded in various sectors of society, which are usually based on personal views arising from differences in culture, religion, class, education, politics, or age.

Communicative planning approaches have been called upon in planning and design domains where there are a range of competing stakeholders and where the distribution of decision making power is highly dispersed across different sectors. Community design that incorporates communicative approaches allows for uncertainty and conflict in its processes. It encourages community outreach and attempts to foster socio-political will among the stakeholders by promoting structured dialogue.

\section{UNCERTAINTY IN COMMUNITY DESIGN}

Humans have always pondered the future and wondered how they might be able to anticipate change, particularly in areas over which they have little control (Schwartz, 1991).

For several decades, planners and designers, tasked to help envision the future, have recognized the need to prepare for future community needs and challenges through structured planning and design activities with a hope that the future can somehow be created following planned investments and fall within reasonable expectations. However, a community's future remains an uncertain one. The number of factors that influence whether development occurs and to what extent it takes place is enormous. Moreover, past trends and the knowledge generated from them are not necessarily the direction communities wish to head.
Consequently, scenario planning has grown in use recently, particularly that which is referred to as visioning (Bartholomew 2005). Over the course of the past decade and a half, planners, designers, and citizens increasingly articulated priorities and values to help shape the futures of their communities. Through scenario planning, the wide-open question of what the future might bring can be narrowed down to a more manageable set of possibilities.

\section{WHAT IS SCENARIO?}

A scenario is "an internally consistent view of what the future might turn out to be; not a forecast, but one possible future outcome" (Porter, 1985, p. 446). Fundamentally, scenarios are stories about the future (Ogilvy, 2002). They need not, and indeed cannot, predict precisely. Rather, each should present a vision of the future that is plausible in light of known information (Ringland, 2002).

Following Bartholomew (2007) and Smith (2007), most scholars trace the origin of scenario planning to the RAND Corporation (Kahn, 1962) and its application to business to the Royal Dutch Shell (Wack, 1985). In its earliest stages, scenario planning was used as a way to consider multiple facets of a problem simultaneously, as well as a tool to help decision makers who had limited backgrounds and resources address the uncertain future. It fostered imagination and facilitated critical thinking about how a future might unfold. It has been widely used in disciplines ranging from business to conflict resolution to the military (Andrews, 1992; van der Heijden, 1996).

\section{SCENARIO PLANNING IN COMMUNITY DESIGN}

The scenario planning practices that emerged in the 1990s essentially grafted the military and business approaches onto to the more customary planning structures of the continuing, cooperative, and comprehensive $(3 \mathrm{C})$ process required by the Federal Aid Highway Act of 1962 and the environmental impact reporting requirements of the National Environmental Policy Act (NEPA) (Bartholomew, 2005).

The typical scenario planning process compares one or more alternative future community design scenarios to a trend scenario. In the trend scenario, urban development and infrastructure investment patterns of the recent past are assumed to continue to the planning horizon 20 to 50 years in the future and the impacts of this on the study area are assessed. This is followed by the formulation of one or more alternative futures that differ from the trend with respect to community design and growth (Lee, 2016). Essentially, scenario planning assumes that if planners and designers consider multiple futures, they are more likely to make better decisions. 


\section{Scenario Planning Software}

\section{Models \& Apps for Scenario Planning}

\section{Web Portal}

\section{Data Quality Wizard}

\section{D Modeling Engine}

Figure 1. The Sustainable Places analytical tools suite developed by UT CSD in collaboration with Fregonese Associates and Texas Advanced Computing Center.

\section{THE INFLUENCE OF IT ADVANCE ON SCENARIO} PLANNING / GIS-ENABLED SCENARIO PLANNING TOOLS Aided by substantially expanded computing capacity and methods, especially in the area of geospatial technologies with advances in visualization and spatial analytics, scenario planning expanded considerably over the past two decades, becoming common enough to be considered state-of-the-practice (Ewing, 2007). Many agencies and private firms were involved in this growth; however, the work of Peter Calthorpe and John Fregonese was particularly instrumental in popularizing the technique (Goodspeed, 2013).

The adoption of GIS (Geographic Information Systems) technology by professional planners, and the emergence of a dominant GIS software package and data formats in the 1990s, enabled the development of this new class of computer tools which could rely on the GIS software for data management, visualization, and other functions. In particular, the ArcGIS software suite produced by the software company ESRI has become a monopoly provider of GIS software, enabling them to also effectively define file formats and analytical workflows.
The analytical and mapping functions offered by GIS-enabled scenario analysis tools estimate and illustrate likely effects and potential costs of various community growth and development patterns portrayed by multiple scenarios. This expansion included the development of a new class of scenario planning tools in the 1990s such as CommunityViz, INDEX, I-PLACE3S, What-if, and Envision Tomorrow. Klosterman argued that these tools present a variety of technical and functional approaches that are necessary to support community designers in their daily tasks.

\section{SOCIO-TECHNICAL PERSPECTIVE}

These scenario planning tools are designed to take advantage of modern geospatial technologies to support a planning and design process that is characterized by communication and collective design.

Key characteristics that are shared by these GIS-enabled scenario planning practices and techniques include: 1) a focus on spatial development patterns typically in the form of physical design; 2) extensive use of spatial data, geographic analysis, and visualization; 3 ) the involvement of multiple types of stakeholders through public participation. 


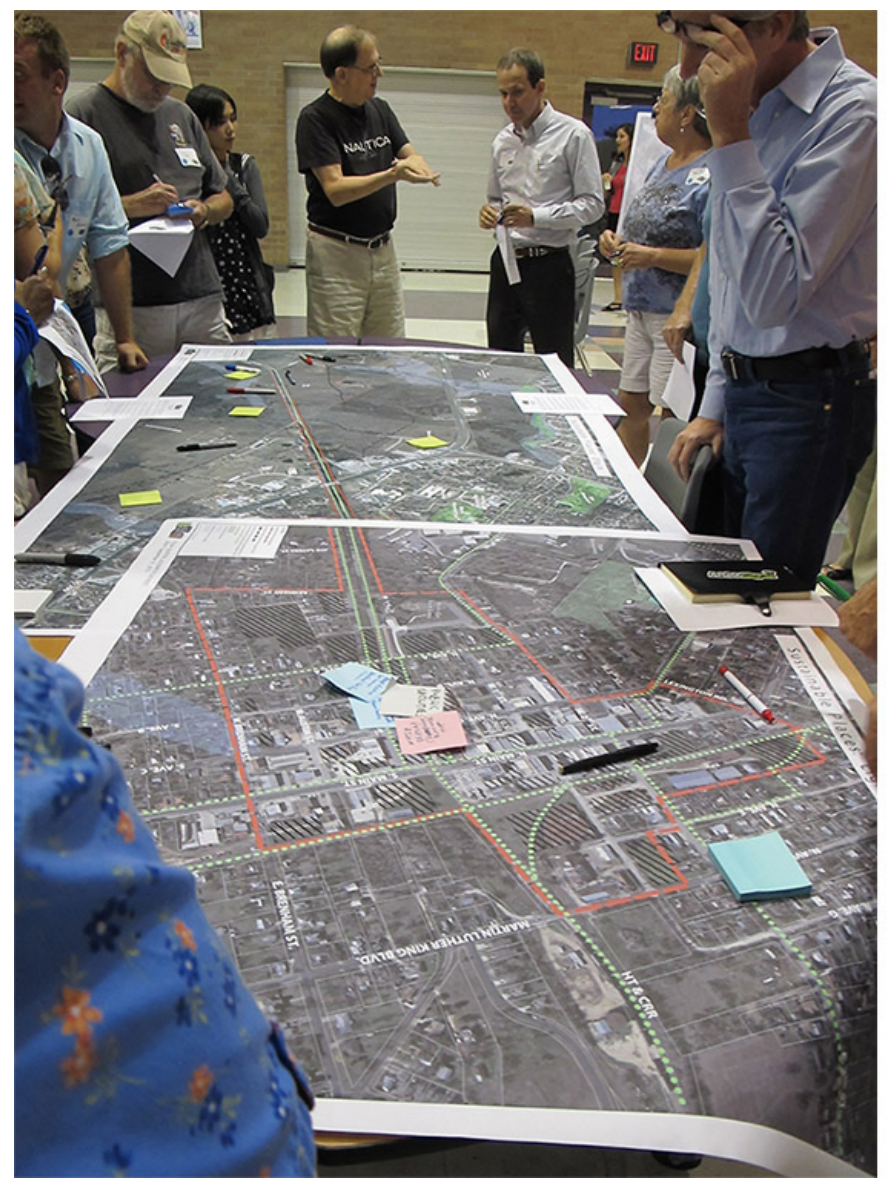

Figure 2. Vision workshop conducted in City of Elgin, Texas.

This type of community design practice takes on a unique approach that seeks to integrate social and technical dimensions of design. This socio-technical perspective is essential to examine this particular genre of design, which can only be understood through an interdisciplinary lens fused with science, technology, and society (STS) (Bijker and Law 1992; Hackett 2008). It emphasizes the importance of investigating technology and social contexts together in order to both develop methodology and improve problem-driven technology.

Therefore, this study sees this class of GIS-enable scenario planning tools not as a freestanding technology in a laboratory setting, but as they are applied in real-world projects with specific socio-political settings. It is with this view that this study is structured.

\section{CASE STUDY}

This section presents a scenario planning project as a case study. It starts with a brief description of the case contexts, including its geographic area, organizational structure, and a project overview. This background information is followed by detailed descriptions of two key aspects of the project: 1) the development of five technical components supporting the scenario planning process; 2 ) the design and implementation

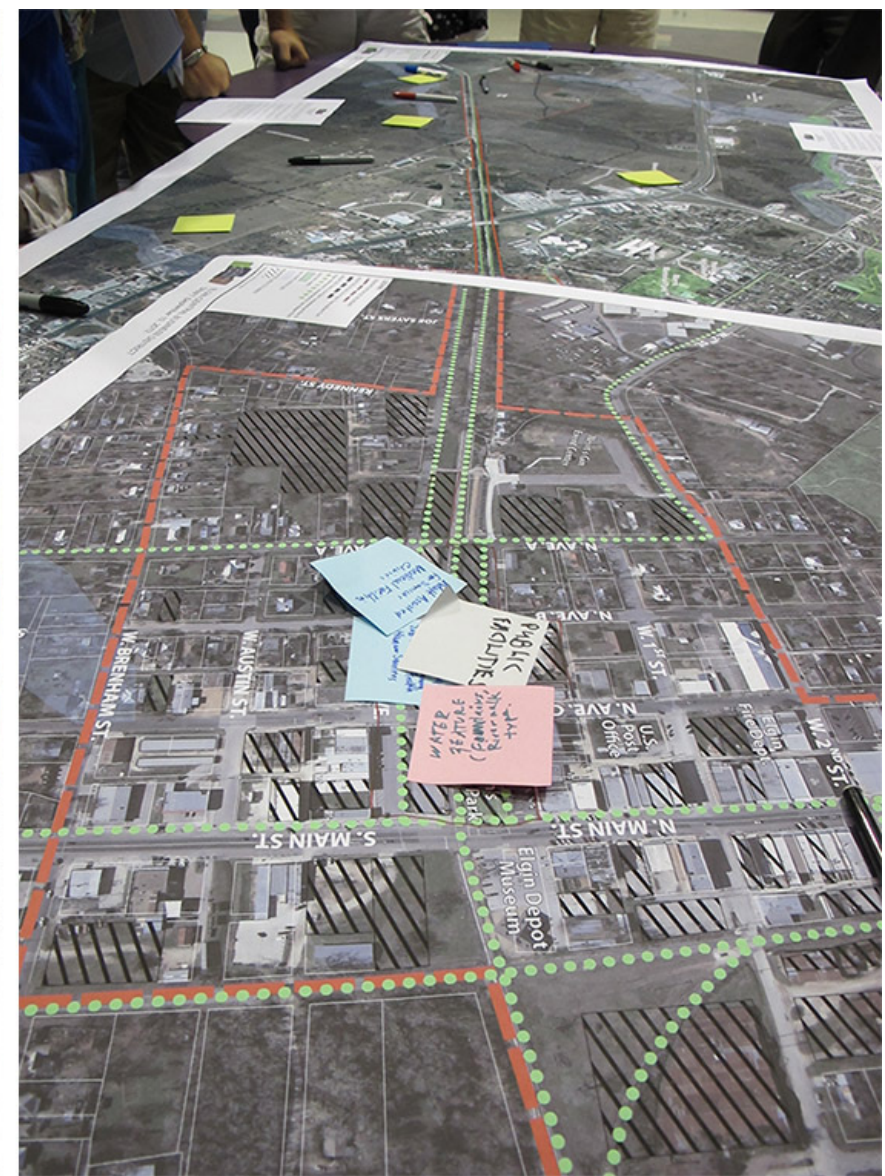

of public outreach and engagement activities enabling communication and collaboration among key stakeholders in the project.

\section{THE CONTEXTS}

The Austin-Round Rock-San Marcos five-county metropolitan region is experiencing economic growth that brings prosperity as well as threats to quality of life. As the region adds over 60,000 new residents annually, housing affordability is decreasing, traffic congestion is worsening, and growth is outpacing region's ability to manage this change.

To address these challenges, the Capital Area Council of Governments (CAPCOG) and the Capital Area Texas Sustainability Consortium (CATS) led an effort to apply for a HUD Sustainable Communities Regional Planning Grant, which they were awarded a \$3.7 million dollar in 2010.

Called the Sustainable Places Project, this large-scale planning effort brought together local governments, regional organizations, researchers from the University of Texas at Austin (UT), and stakeholder groups to develop strategies that will guide the region in the planning of activity centers around Central Texas and advance region's plan and vision for sustainable development. 


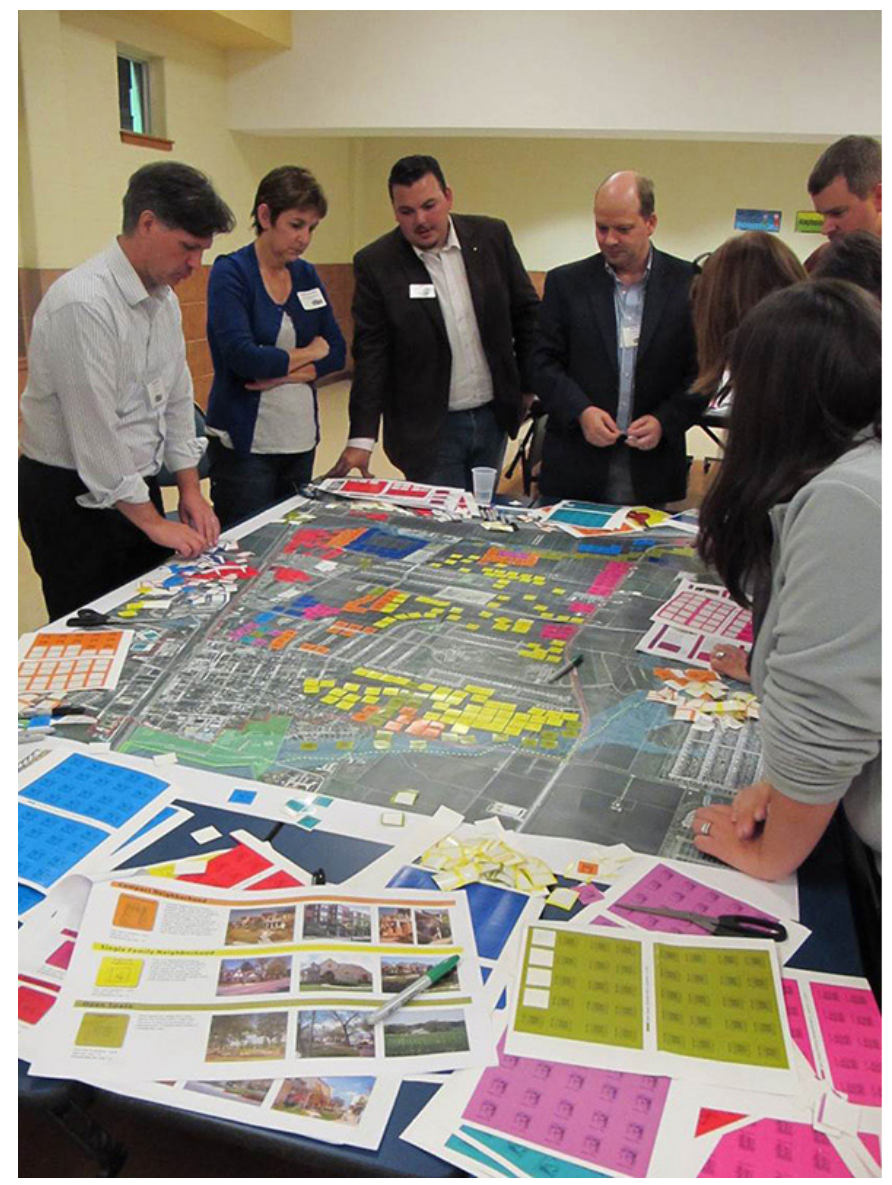

Figure 3. Design charrette held in City of Hutto, Texas.

The consortium implemented three strategies related to the activity centers: 1) develop an analytical tool suite; 2 ) conduct demonstration projects as selected activity center sites; 3 ) conduct a program of citizen engagement (CAPCOG, 2012).

CAPCOG identified the activity centers that would serve as demonstration sites, and selected sub-consultants through a request for proposals to conduct community planning and design work and public outreach programs for the demonstration projects.

The selected teams included Austin-based urban design firm McCann Adams Studio, which was tasked to conduct most of the key planning and design activities, and public relations firm Hahn, Texas, which was in charge of public outreach, and Portland-based Fregonese Associates, which was responsible for technical assistance and consultations on scenario planning.

A research group formed by a number faculty members and graduate student assistants at UT led the development of the analytical tool suite, in close collaboration with Fregonese Associates and their partners at the University of Utah.

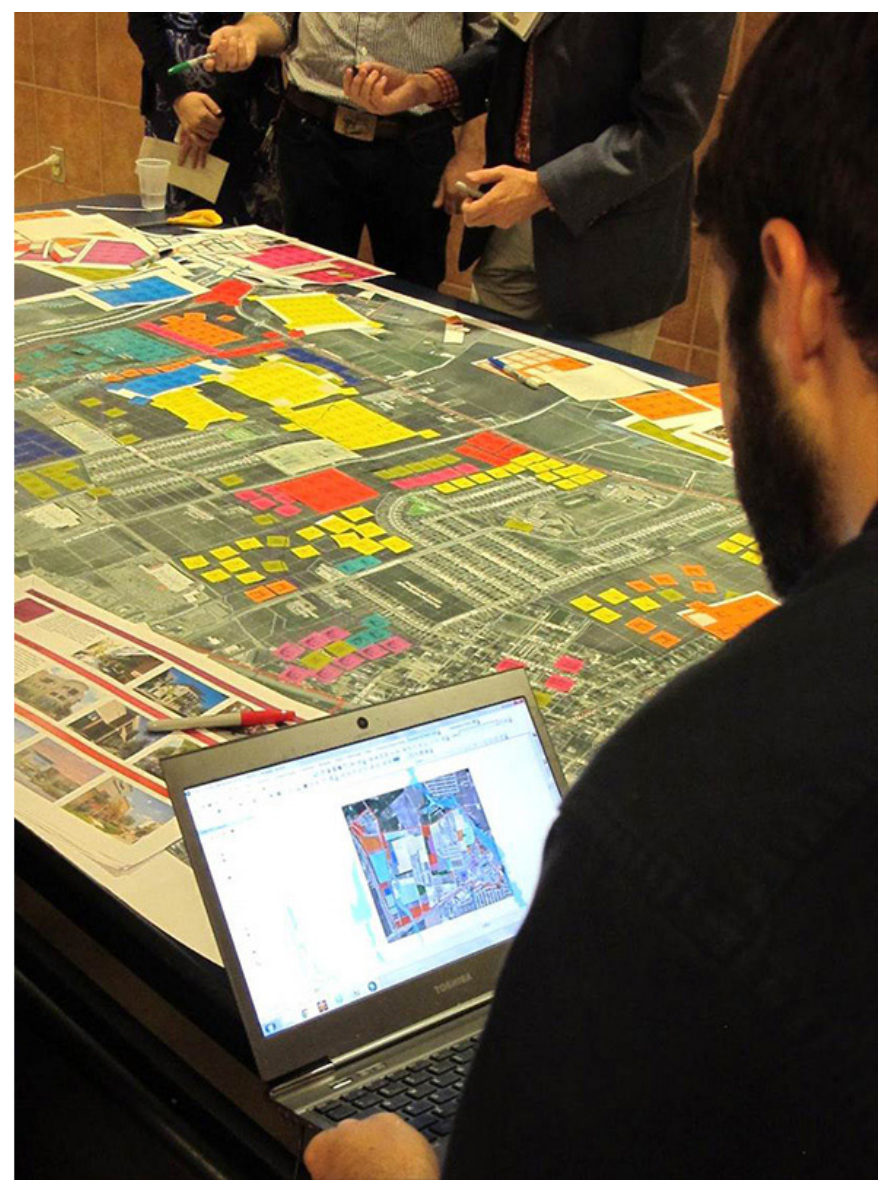

The five demonstration sites, selected by CAPCOG from among nine applicants, were South Shore District in Austin, Dripping Springs, Elgin, Hutto, and Lockhart.

\section{TECHNICAL FRAMEWORK}

One element that represents the technical dimension of the project is the development of a GIS-based analytical tools suite aimed to support local planning agencies to conduct scenario planning. The Center for Sustainable Development (CSD) at UT led this effort. In close collaboration with partners from both public and private sectors, five key software components have been developed, including: 1) an enhanced scenario planning software plug-in for the ArcGIS platform; 2) a set of "Apps" to be added to the scenario planning platform; 3) a client-server database schema and a data quality control interface to support the exchange of GIS data between a wide variety of scenario planning tools, 4) a web-based scenario publishing interface for leveraging public input; 5) a procedural 3-D modeling engine for automating 3-D spatial data visualizations (CSD, 2014). (Figure 1)

\section{PUBLIC OUTREACH PROCESS / THE SOCIAL ASPECT}

The other important element that represents the social dimension of the project is the establishment of a broadbased citizen engagement program. Several rounds of public involvement at the demonstration sites were conducted. For 


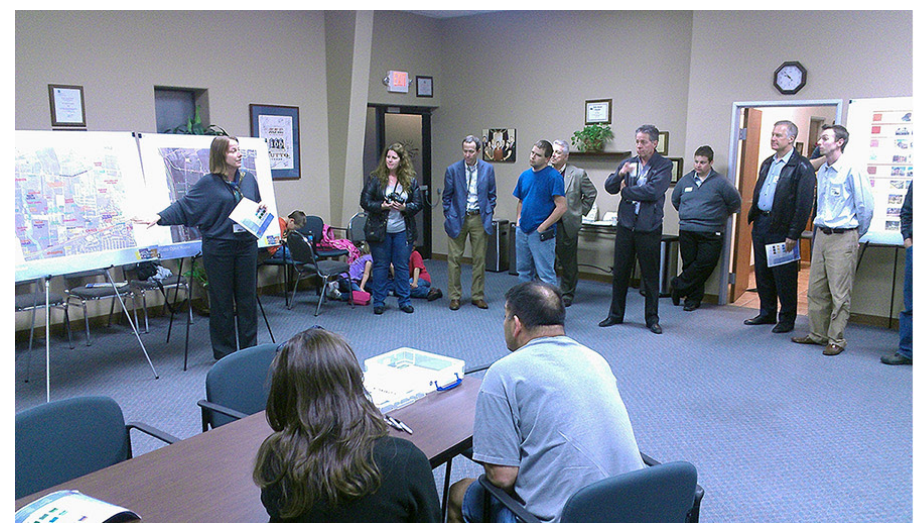

Figure 4. Open house conducted in City of Elgin, Texas.

each demonstration site, a local advisory committee was convened to represent the diverse interests of the community, and three workshops were planned.

At the first, vision workshops, participants learned about the project goals and provided comments to describe the kind of place their community should become for the next generation. Through a small-group mapping exercise, initial ideas for what and where future changes may occur were recorded with "Post-It" notes placed directly upon a large aerial map of the demonstration sites. (Figure 2)

The next set of workshops, the "design charrettes," involved a sketch mapping exercise that featured a digitizer to operate Envision Tomorrow (the software tool chosen for the project), who also verbally reported back to the discussion of the scenario outputs in the end of each workshop. A paper-based mapping process was used alongside as the inputs to Envision Tomorrow.

The charrette activity was based on residents' visions of where specific development types should be located. Each development type, represented by a type of chips, is based on a certain mixture of building types and uses, which also represent certain numbers of jobs and households. The participants formed groups and each one had a menu of development types with jobs and housing details along with example images. The groups then arranged "chips" that corresponded to the development types on a map of the demonstration site. Each group's map was digitized in real time using the analytic software, allowing participants to understand the effect of their decisions on various indicators. This particular workshop allowed participants to translate their visions into more specific development scenarios for the demonstration site. (Figure 3)

Finally, open houses were conducted for each of the demonstration sites to present three scenarios based upon the charrette results (Figure 4). Two of the scenarios were designed to "bracket" the range of ideas expressed by the

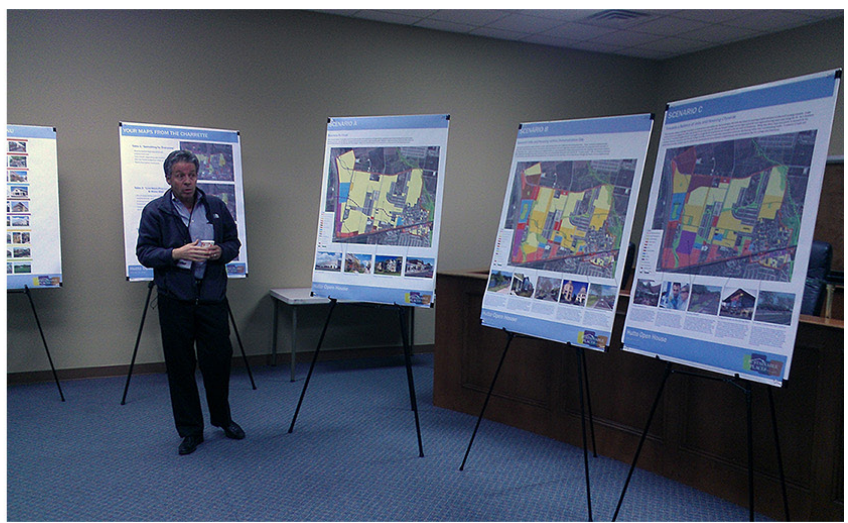

community at the design charrette, while the third was developed as a "baseline" example of "business as usual", reflecting current, dominant development trends of single-family housing on the site (Figure 5). Through a survey conducted at the meeting and subsequently online afterwards, residents stated preferences and offered further suggestions for the refinement of the community design concepts. The final refined plans, which provide specific recommendations regarding the overall land use plan and the types of public and private investments that could jumpstart the community's visions for the demonstration sites, were formally presented at public meetings of official bodies.

\section{DISCUSSION / CONCLUSION}

The Sustainable Places Project (SPP) by CAPCOG discussed in this study is only one of many similar scenario planning efforts funded by HUD's latest rounds of Sustainable Communities Initiative over the past few years. Other projects include Wasatch Choice for 2040 for the Salt Lake City metropolitan region, Connect Our Future Project covering 14 counties across North and South Carolina, and Creating Sustainable Places Project by Mid-America Regional Council for the Kansas City metropolitan region in Missouri. One of the many characteristics shared by these projects is that they all incorporated GIS-based techniques into their community planning and design processes in order to: 1) collect and analyze data; 2) promote and sustain broad-based citizen involvement; 3 ) create and evaluate alternative development choices for the future of their communities.

As discussed earlier, GIS-enabled scenario planning seeks to booster the technical efficacy of spatial analysis in community planning and design as well as to build transparent channels for communications and open platforms for participations necessary for the design process.

This socio-technical perspective is important to understand the significance of this particular type of community design, which seeks to integrate social practices of design with information and communication technologies. It is again through this particular viewpoint that four key final 


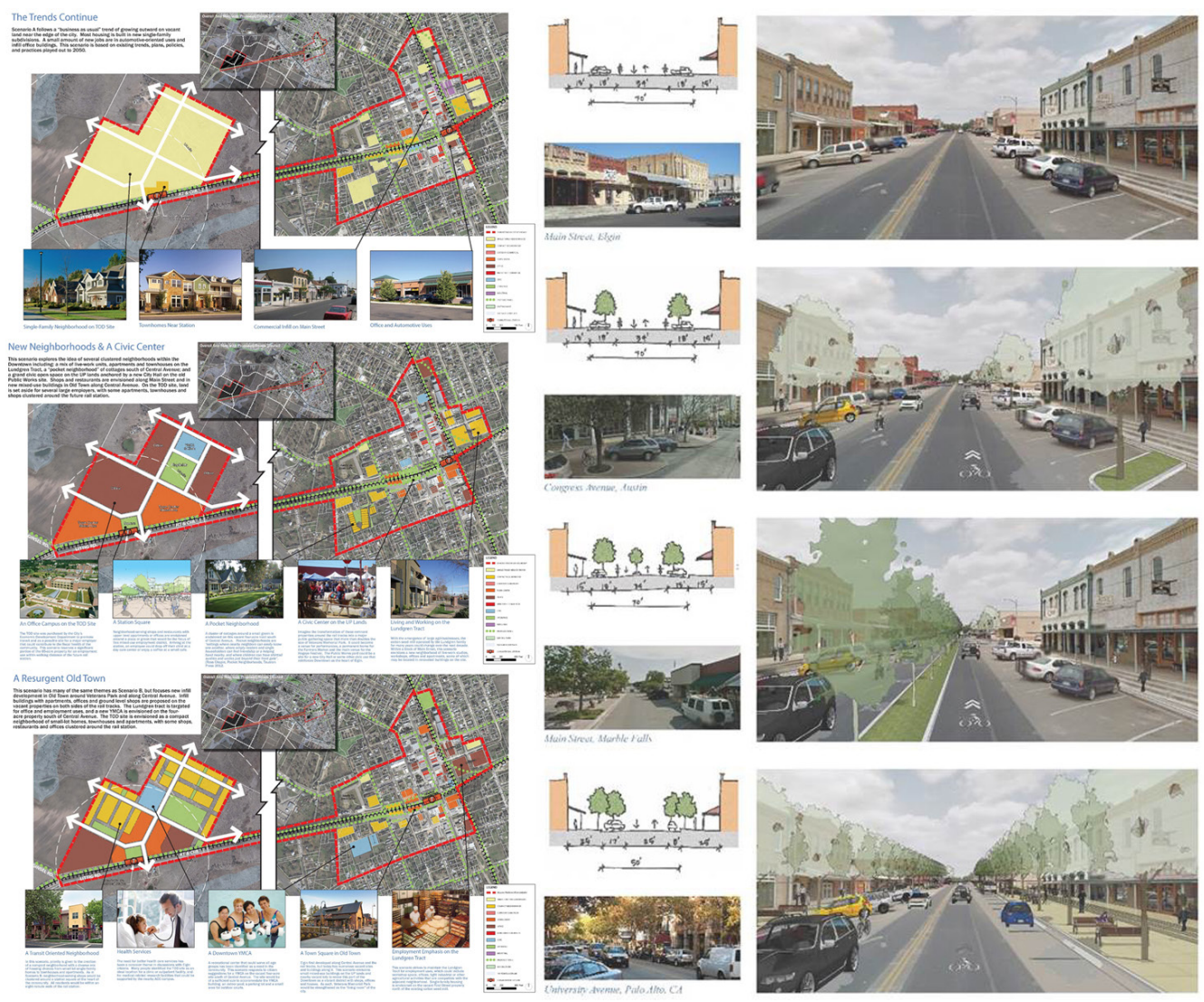

Figure 5. Three community design scenarios along with illustrations of possible streetscape designs displayed during the open house event in City of Hutto, Texas.

observations about the interplays between the two aspects are drawn as the follow:

1. Technology enables scientific inquiry and increases understandings of social, economic, and natural systems

The ability of these geospatial technologies to conduct analyses and to illustrate the results of such analyses substantially increased designers' ability to engage and educate the public about the rational/scientific aspect of various key factors involved in the design process. Those analytical modules added into the scenario planning tools, such as Envision Tomorrow, help make scientific knowledge, theories, or existing best practices for different key issues understandable to the general public and other stakeholders.

2. Technology allows collaborative design and enables quick exploration and performance evaluation on design alternatives

Scenario planning tools allow users to generate and compare various community design scenarios that represent different design alternatives. The Envision Tomorrow program, with its GIS-enabled digital map as the canvas, provides the users a sketching interface to quickly paint different combinations of design prototypes, which can then be tested and refined based on identified parameters and performance measures to produce a more sustainable solution that reflects the consensus among the users participating in this collaborative process.

3. Technology helps identify community values and promotes social learning

The continuous public engagement and public education about the potential benefits of alternative growth strategies help build durable, inclusive consensus within the community over time. Various techniques used in this case, including online surveys, keypad polling activities in workshop settings, identifications of key performance indicators tailored to each site, and developments of scenarios with the GIS-based tool, all afforded the participating residents in the demonstration sites the opportunities to express their concerns, raise issues facing their respective community, and together identify key values that are essential to the future of their communities. The success of this value-seeking and social learning process requires effective ongoing public relations and sophisticated representation of reliable, complex, and convincing data that are made possible by scenario planning tools.

4. Technology helps shape political coalitions and build organizational capacity 
Although public input was extensive through a series of public workshops, the success of this type of scenario planning was very dependent on the delicate political sensibility of the early leadership of the Consortium. Getting the buy-in of key "brass roots" players before starting the process has been a formula for minimizing resistance in the long run. This coalition build-up process was assisted by some of the technical procedures in the scenario planning process. In the early phrase of the project, led by UT CSD, a collective effort was made together by many different institutes or governmental units to formulate an initial list of potential indicators and benchmarks for performance evaluations. This step allowed all parties to exchange ideas, share concerns, understand the scope of the project, and more importantly learn the necessary procedures, data requirements, and methods for presentation to effectively run the scenario planning tools suite. These technical components, including the performance indicators, available data through online sharing, the scenario painting interface, and all the media for scenario presentation and reporting, increase the ability of these participating organizations to convey their work and provide convincing evidence for their consensus building strategies with the general public.

Despite of the successful completion in early 2014, the Sustainable Places Project was not without limitations. A number of un-fulfilled efforts hampered a complete realization of the initial dream of building a new toolkit for planners and designers.

Nevertheless, the tools suite that was developed out of this three-year-long scenario planning effort helped turn ad hoc community development into better planning by clearly revealing the true impact of incremental community changes over time with the use of simple diagrams and clear charts generated by reliable data and innovative GIS-enabled digital tools. In addition to the adaption of modern technologies, the process of plan-making can be as important as the tools themselves. Through community collaboration, creativity, and careful consideration of the long-term impact of design choices, communities across the nation can design better, more livable futures.

\section{ENDNOTES}

1 Andrews, C.J. (1992). "Sorting out a consensus: Analysis in support of multiparty decisions." Environment and Planning B: Planning and Design, 19 (2): 189-204.

2 Bartholomew, K. (2005). Integrating Land Use Issues into Transportation Planning: Scenario Planning Summary Report. Washington, DC: Federal Highway Administration, U.S. Department of Transportation. http://www.trb. org/news/blurb_detail.asp?id=5689.

3 Bartholomew, K. (2007). Land-use Transportation Scenario Planning: Promise and Reality. Transportation, 34 (4): 397-412.

4 Bijker, W.E. \& Law, J. (1992). Shaping Technology/Building Society: Studies In Sociotechnical Change. Cambridge, Massachusetts: MIT Press.

5 CAPCOG - Capital Area Council of Governments. (2012). Capital Area Texas Sustainability Consortium Workplan: HUD Sustainable Communities Regional Planning Grant.
6 CSD - The Center for Sustainable Development. (2014). Sustainable Places Project: Analysis and Visualization of Alternate Futures. The University of Texas at Austin. http://www.soa.utexas.edu/csd/research/sustainable-places.

7 Ewing, R. (2007). "Research You can Use: Regional Scenario Plans and MetaAnalysis." Planning, 73 (3): 38.

8 Goodspeed, R. (2013). Planning Support Systems for Spatial Planning Through Social Learning. Doctoral dissertation submitted to the Department of Urban Studies and Planning, MIT.

9 Hackett, E. J. (2008). The Handbook of Science and Technology Studies. 3rd Ed Cambridge, Massachusetts: MIT Press.

10 Healey, P. (1997). Situating Communicative Practices: Moving Beyond Urban political economy. Planning Theory, 17: 65-82.

11 Healey, P. (1992). Planning Through Debate: The Communicative Turn in Planning Theory. Town Planning Review, 63 (2): 143-62.

12 Kahn, H. (1962). Thinking About the Unthinkable. Ann Arbor, Michigan: University of Michigan Press.

13 Kliskey, A. D. (1995). "The Role and Function of a GIS as a Planning Tool in Natural Resource Management." Computers, Environment and Urban Systems. 19 (1): 15-22.

14 Lee M. C. (2017) From Blue-Printing to Finger-Printing: Building Healthy Communities with Scenario Planning. In: Geertman S., Allan A., Pettit C., Stillwell J. (eds) Planning Support Science for Smarter Urban Futures. CUPUM 2017. Lecture Notes in Geoinformation and Cartography.

15 Lee, M.-C. (2016) Geodesign Scenarios. Landscape and Urban Planning, 156: 9-11.

16 Ogilvy, J. (2002). Creating Better Futures: Scenario Planning as a Tool for a Better Tomorrow. New York: Oxford.

17 Porter, M. (1985). Competitive Advantage: Creating and Sustaining Superior Performance. London: Free Press.

18 Ringland, G. (2002). Scenarios in Public Policy. New York: John Wiley.

19 Scholten, H. J. \& Stillwell, J. C. H. (1990). Geographical Information Systems: The emerging requirements. In H. J. Scholten \& J. C. H. Stillwell (Eds.), Geographical information Systems for Urban and Regional Planning. Netherlands: Kluwer Academic Press.

20 Schwartz, P. (1991). The Art of the Long View. New York: Double Day.

21 Smith, E. (2007). Using a scenario approach: From business to regional futures. In L. D. Hopkins \& M. A. Zapata (Eds.), Engaging the future: Using Forecasts, Scenarios, Plans, and Projects (pp. 79-101). Cambridge, MA: Lincoln Institute of Land Policy.

22 van der Heijden, K. (1996). Scenarios: The Art of Strategic Conversation. Chichester, UK: John Wiley \& Sons.

23 Wack, P. (1985). "Scenarios: Uncharted Waters Ahead." Harvard Business Review 63 (5): 73-89. 